\title{
EFEITO DA DISPONIBILIDADE DE NITRATO EM SOLUÇÃO NUTRITIVA SOBRE A ABSORÇÃO DE NITROGÊNIO E ATIVIDADE ENZIMÁTICA DE DUAS CULTIVARES DE ARROZ $\left({ }^{1}\right)$
}

\author{
ANDRÉ MARQUES DOS SANTOS $\left(\left(^{*}\right)\right.$, CARLOS ALBERTO BUCHER $\left({ }^{3}\right)$, \\ ELVIA MARIAM LIS MARTINEZ STARK $\left({ }^{4}\right)$, MANLIO SILVESTRE FERNANDES $\left({ }^{5}\right)$, \\ SONIA REGINA SOUZA $\left({ }^{4}\right)$
}

\begin{abstract}
RESUMO
Duas cultivares de arroz, Piauí (tradicional) e IAC-47 (melhorada), foram colocadas em solução nutritiva contendo $20 \mathrm{mg}$ de $\mathrm{N}_{-\mathrm{NO}_{3}}{ }^{-} \mathrm{L}^{-1}$ até 32 dias após a germinação (DAG). Depois disso, um grupo de plantas passou a receber $200 \mathrm{mg}$ de $\mathrm{N}-\mathrm{NO}_{3}{ }^{-} \mathrm{L}^{-1}$, enquanto o outro continuou recebendo $20 \mathrm{mg}$ de $\mathrm{N}-\mathrm{NO}_{3}{ }^{-} \mathrm{L}^{-1}$ até os $42 \mathrm{DAG}$. De 42 até os $56 \mathrm{DAG}$, todas as plantas receberam $5 \mathrm{mg}$ de $\mathrm{N}_{-N_{3}}{ }^{-} \mathrm{L}^{-1}$ até o fim do ciclo. Esses tratamentos foram empregados visando simular o fluxo sazonal de nitrato existente nos solos de regiões tropicais. As plantas foram coletadas aos 133 DAG e separadas em folha bandeira, folha 2, colmos e raízes. Foram determinados os teores de $\mathrm{N}$ na forma de aminoácidos, nitrato e amônio, açúcares solúveis, atividades da nitrato redutase (NR) e glutamina sintetase (GS). O fluxo sazonal de nitrato influenciou significativamente a absorção e o uso de N. As variedades estudadas foram responsivas de maneira diferenciada em relação ao acúmulo e à translocação de $\mathrm{N}$, quando submetidas ao fluxo sazonal de nitrato. A cultivar Piauí parece acumular mais $\mathrm{NO}_{3}^{-}$em seus tecidos na fase inicial do seu ciclo, podendo permitir sua posterior translocação. A folha bandeira e folha 2 parecem atuar como local preferencial de acúmulo de N, sendo este acúmulo mais intenso na cultivar Piauí.
\end{abstract}

Palavras-chave: N-amino, enzimas de assimilação de nitrogênio, absorção de nitrato, Oryza sativa L., açúcares solúveis, variedades tradicionais.

\section{ABSTRACT \\ EFFECT OF NITRATE AVAILABILITY IN NUTRIENT SOLUTION ON NITROGEN UPTAKE AND ENZIMATIC ACTIVITY OF TWO RICE CULTIVARS}

Two rice cultivars, Piaui (a landrace) and IAC-47 (an improved variety), were grown in nutrient solution containing $20 \mathrm{mg}$ nitrate $\left({\mathrm{N}-\mathrm{NO}_{3}}^{-}\right) \mathrm{L}^{-1}$ up to 32 days after germination (DAG). After this, a group of plants received $200 \mathrm{mg} \mathrm{N}-\mathrm{NO}_{3}{ }^{-} \mathrm{L}^{-1}$, while the other was kept at $20 \mathrm{mg} \mathrm{N}-\mathrm{NO}_{3}{ }^{-} \mathrm{L}^{-1}$ up to 42 DAG. From 42 until 56 DAG, all plants received $5 \mathrm{mg} \mathrm{N}-\mathrm{NO}_{3}{ }^{-} \mathrm{L}^{-1}$ until the end of the cycle. These treatments were applied with the objective to simulate nitrate flush in tropical regions. Plants were collected at 133 DAG and separated in to leaf flag, leaf 2, stem and roots. $\mathrm{N}$ contents in amino acids, nitrate and ammonium forms, soluble sugars, nitrate reductase (NR) and glutamine synthetase (GS) enzymatic activities were determined. The evaluated varieties replay in different manner about accumulate and translocation nitrate. The variety Piaui seems to accumulate $\mathrm{more} \mathrm{NO}_{3}{ }^{-}$ in the tissues at the initial phases of its cycle, allowing subsequent remobilization. Flag leaf and leaf 2 seem to act as preferential sites of $\mathrm{N}$ accumulation, being this accumulation more intense in the landrace variety.

Key words: amino-N, nitrogen assimilation enzymes, nitrate uptake, Oryza sativa L., soluble sugars, traditional varieties.

(1) Recebido para publicação em 23 de outubro de 207 e aceito em 4 de outubro de 2008.

$\left({ }^{2}\right)$ Doutorando do Curso de Pós Graduação em Agronomia-Ciência do Solo - CPGA-CS/UFRRJ. E-mail: andrmarques@yahoo.com.br $\left(^{*}\right)$ Autor correspondente.

$\left({ }^{3}\right)$ Mestrando do CPGA-CS.

$\left({ }^{4}\right)$ Departamento de Química, Universidade Federal Rural do Rio de Janeiro, UFRRJ, BR 465 km 07, 23890-000 Seropédica (RJ).E-mail: soniabq@ufrrj.br

$\left({ }^{5}\right)$ Departamento de Solos, Universidade Federal Rural do Rio de Janeiro, Seropédica (RJ). 


\section{INTRODUÇÃO}

Os cereais são fontes de proteínas e, principalmente, de carboidratos à dieta humana, contribuindo com aproximadamente $45 \%$ da dieta protéica humana (FAO, 1998). Dentre os cereais, o arroz tem sido a fonte primária de alimento para mais da metade da população mundial, sendo cultivado anualmente em aproximadamente 154 milhões de hectares, correspondendo a cerca de $11 \%$ das terras cultivadas no mundo, representando aumento de $130 \%$ na sua produção entre 1966 e 2000 (KHUSH, 2005).

A importância do arroz é ainda maior para as populações de baixa renda que cultivam este cereal em lavouras de subsistência, utilizando-o como seu principal alimento. A agricultura do Estado do Maranhão está baseada na utilização de variedades tradicionais de arroz, oriundas de regiões onde a disponibilidade de nutrientes é limitante. Estudos realizados com essas variedades têm evidenciado sua maior eficiência quanto à aquisição e ao uso de nitrogênio (N) (SouzA et al., 1998; RodRIGUes et al., 2004; SOUZA e FERNANDES, 2006).

O uso de fertilizantes nitrogenados inorgânicos está associado a uma gama de problemas ambientais e a previsão é de que seu uso vai dobrar ou triplicar nos próximos 50 anos (Tilman et al., 2001). Atualmente, problemas relacionados ao custo destes fertilizantes e a poluição por $\mathrm{NO}_{3}{ }^{-}$têm levado à seleção de variedades que absorvam e metabolizem o nitrogênio do solo mais eficientemente.

Segundo Greenland (1958) e Wetselaar (1961a, b), o clima tropical, caracterizado por duas estações bem definidas (um período de chuvas e um período seco), ocasiona fluxos sazonais de nitrato no solo. O mesmo fenômeno parece ocorrer nas regiões do cerrado brasileiro, onde houve acúmulo de $\mathrm{N}^{-} \mathrm{NO}_{3}{ }^{-}$ no solo em curto período de tempo na estação chuvosa (Nardoto e Bustamante, 2003). Desta forma, o N está sujeito à lixiviação mais intensa durante a estação das chuvas, tornando-se disponível para as plantas apenas no início do período úmido, portanto, devendo ser absorvido rapidamente.

Resultados verificados com cultivares tradicionais de arroz indicam a necessidade de mais estudos que visem ao entendimento dos mecanismos relacionados à absorção e remobilização do N. Desse modo, foi desenvolvido um experimento simulando a disponibilidade sazonal de $\mathrm{N}$ em solução nutritiva, com o objetivo de avaliar o comportamento de uma cultivar de arroz tradicional do Maranhão (Piauí), em comparação a uma melhorada (IAC 47), quanto à absorção de $\mathrm{N}$ (N-total, $\mathrm{N}^{-\mathrm{NH}_{4}}{ }^{+}, \mathrm{N}^{-} \mathrm{NO}_{3}{ }^{-}, \mathrm{N}$-amino livre) e atividade enzimática (nitrato redutase e glutamina sintetase), em diferentes partes das plantas.

\section{MATERIAL E MÉTODOS}

O experimento foi desenvolvido em casa de vegetação no Departamento de Solos da Universidade Federal Rural do Rio de Janeiro. Após a germinação, as plântulas (duas por vaso de $5 \mathrm{~L}$ ) receberam solução nutritiva de Hoagland modificada, pH 5,5 (HoAgland e ARNON, 1950), contendo $20 \mathrm{mg}$ de $\mathrm{N}-\mathrm{NO}_{3}{ }^{-} \mathrm{L}^{-1}$, até 32 dias após a germinação (DAG). Aos $32 \mathrm{DAG}$ um grupo de plantas passou a receber $200 \mathrm{mg}$ de $\mathrm{N}_{-} \mathrm{NO}_{3}{ }^{-} \mathrm{L}^{-1}$, até completarem 42 DAG, a partir dos quais todas as plantas passaram a receber $5 \mathrm{mg}$ de $\mathrm{N}-\mathrm{NO}_{3}{ }^{-} \mathrm{L}^{-1}$ até o fim do ciclo. Os tratamentos foram aplicados de forma que simulasse o fluxo sazonal de nitrato que ocorre nos solos existentes nas regiões tropicais, como no cerrado, por exemplo. $\mathrm{O} \mathrm{pH}$ da solução nutritiva foi corrigido diariamente, a fim de permanecer com $\mathrm{pH}$ 5,5, e o volume mantido constante por meio de adição de água destilada. A solução nutritiva foi trocada a cada três dias.

A coleta do material vegetal foi realizada ao fim do ciclo da cultura (133 DAG). As plantas foram separadas em folha bandeira (FB), folha 2 (F2), colmo (C) e raízes (R). Amostras de FB, F2 e $\mathrm{R}$ foram coletadas e utilizadas para a determinação da atividade da NR (JAWORSKI, 1971) e da GS (FARNDEN e ROBERTSON, 1980) no mesmo dia da coleta. Amostras de um grama de tecido vegetal (FB, F2, C e R) foram homogeneizadas em $20 \mathrm{~mL}$ de etanol $(80 \%)$ e após partição com clorofórmio em igual volume da solução alcoólica (FERnANDes, 1984), a fração solúvel obtida foi armazenada e utilizada posteriormente para determinar os teores de $\mathrm{N}$-amino livre (YeMm e Cocking, 1955), açúcares solúveis (Yemm e Willis, 1957), ${\mathrm{N}-\mathrm{NH}_{4}}^{+}{ }^{+}$(FELKER, 1977) e N-NO ${ }_{3}^{-}$(CATALDO et al., 1975). Também foi avaliado o acúmulo de massa fresca, e no material seco, determinou-se o teor de Ntotal pelo método de Kjeldahl, utilizando-se digestão sulfúrica (Tedesco, 1983).

Utilizou-se o delineamento inteiramente casualizado em um fatorial (duas cultivares, dois níveis de N, quatro partes da planta) com três repetições. Os dados obtidos foram avaliados e submetidos à análise de variância utilizando-se o programa SISVAR para Windows versão 4.0 (FERREIRA, 2000) e as médias foram comparadas pelo Teste de Tukey $(5 \%)$.

\section{RESULTADOS E DISCUSSÃO}

O acúmulo de massa fresca foi maior nos colmos em ambas as variedades, seguido pelas raízes, F2 e FB independentemente da dose de $\mathrm{N}^{-\mathrm{NO}_{3}}{ }^{-}$ utilizada (Tabela 1). 
Tabela 1. Massa Fresca, N-total, ${\mathrm{N}-\mathrm{NH}_{4}}^{+}, \mathrm{N}-\mathrm{NO}_{3}{ }^{-}, \mathrm{N}$-amino livre, açúcares solúveis e atividade das enzimas nitrato redutase e glutamina sintetase ao final do ciclo da cultura (133 DAG) na folha bandeira (FB), folha 2 (F2), colmos

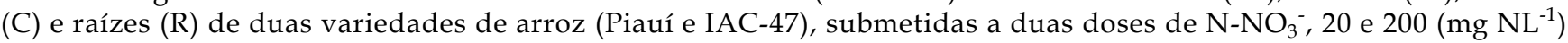

\begin{tabular}{|c|c|c|c|c|}
\hline & \multicolumn{4}{|c|}{ Massa Fresca } \\
\hline & \multicolumn{4}{|c|}{$200 \mathrm{mg} \mathrm{N} \mathrm{L}^{-1^{*}}$} \\
\hline & Piauí & IAC-47 & Piauí & IAC-47 \\
\hline & & & 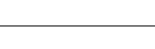 & \\
\hline FB & $3,57 \mathrm{cA}$ & $2,31 \mathrm{cA}$ & $3,12 \mathrm{cA}$ & $2,81 \quad \mathrm{cA}$ \\
\hline $\mathrm{F} 2$ & 3,88 cA & $2,86 \mathrm{cA}$ & $4,57 \mathrm{cA}$ & $3,34 \quad \mathrm{cA}$ \\
\hline $\mathrm{C}$ & 56,31 aA & $49,49 \mathrm{aB}$ & $68,97 \mathrm{aA}$ & $53,98 \mathrm{aB}$ \\
\hline $\mathrm{R}$ & $41,36 \mathrm{bA}$ & $30,89 \mathrm{bB}$ & $44,43 \mathrm{bA}$ & $38,02 \mathrm{bB}$ \\
\hline \multirow[t]{2}{*}{ Média } & 26,28 A & $21,39 \mathrm{~B}$ & 28,99 A & $25,58 \mathrm{~B}$ \\
\hline & \multicolumn{4}{|c|}{$\mathrm{N}$-total, em mg de $\mathrm{N}$ por g de peso seco } \\
\hline & \multicolumn{4}{|c|}{$\mathrm{mg} \mathrm{N} \mathrm{gps}^{-1}$} \\
\hline FB & 20,27 aA & $13,87 \mathrm{aB}$ & $17,24 \mathrm{aA}$ & $13,63 \mathrm{aB}$ \\
\hline $\mathrm{F} 2$ & $15,94 \mathrm{bA}$ & $11,00 \mathrm{bB}$ & $16,94 \mathrm{aA}$ & $10,69 \mathrm{bB}$ \\
\hline C & $6,25 \mathrm{dA}$ & $4,31 \mathrm{~dB}$ & $8,04 \mathrm{bA}$ & $3,69 \mathrm{~dB}$ \\
\hline $\mathrm{R}$ & $7,99 \quad \mathrm{cA}$ & $9,05 \mathrm{cA}$ & $7,62 \mathrm{bA}$ & $8,67 \quad \mathrm{cA}$ \\
\hline \multirow[t]{3}{*}{ Média } & $12,61 \mathrm{~A}$ & $9,56 \mathrm{~B}$ & $12,46 \mathrm{~A}$ & $9,16 \quad \mathrm{~B}$ \\
\hline & \multicolumn{4}{|c|}{$\mathrm{N}-\mathrm{NH}_{4}{ }^{+}$, em $\mu \mathrm{mol} \mathrm{de} \mathrm{NH}_{4}^{+}$por $\mathrm{g}$ de peso fresco } \\
\hline & \multicolumn{4}{|c|}{$\mu \mathrm{mol} \mathrm{g} \mathrm{pf^{-1 }}$} \\
\hline FB & 8,61 aA & $5,49 \mathrm{aB}$ & 5,41 aA & $4,16 \mathrm{aB}$ \\
\hline F2 & $5,98 \mathrm{bA}$ & $3,06 \mathrm{bB}$ & $4,89 \mathrm{aA}$ & $3,54 \quad \mathrm{aB}$ \\
\hline C & $2,23 \mathrm{cA}$ & $1,75 \mathrm{cA}$ & $2,40 \mathrm{bA}$ & 1,41 bA \\
\hline $\mathrm{R}$ & $1,42 \mathrm{cA}$ & $1,14 \mathrm{cA}$ & $1,36 \mathrm{bA}$ & $1,46 \mathrm{bA}$ \\
\hline \multirow[t]{3}{*}{ Média } & $4,56 \quad \mathrm{~A}$ & $2,86 \mathrm{~B}$ & $3,71 \mathrm{~A}$ & $2,55 \quad$ B \\
\hline & \multicolumn{4}{|c|}{$\mathrm{N}-\mathrm{NO}_{3}{ }^{-}$, em $\mu \mathrm{mol}$ de $\mathrm{NO}_{3}{ }^{-}$por $\mathrm{g}$ de peso fresco } \\
\hline & & thes & & \\
\hline FB & 6,82 aA & $4,70 \mathrm{aB}$ & $6,98 \mathrm{aA}$ & $5,62 \mathrm{aB}$ \\
\hline $\mathrm{F} 2$ & 7,03 aA & $3,16 \mathrm{aB}$ & 6,33 aA & 5,78 \\
\hline $\mathrm{C}$ & $2,67 \quad b A$ & $0,42 \mathrm{bB}$ & $4,08 \mathrm{bA}$ & $0,56 \mathrm{bB}$ \\
\hline $\mathrm{R}$ & $1,83 \mathrm{bA}$ & $0,00 \mathrm{bB}$ & $4,50 \mathrm{bA}$ & $1,27 \quad b B$ \\
\hline Média & 4,59 A & $2,07 \mathrm{~B}$ & $5,47 \quad \mathrm{~A}$ & $3,31 \quad B$ \\
\hline
\end{tabular}

$\mathrm{N}$-amino livre, em $\mu$ mol de $\mathrm{N}$-amino por g de peso fresco

\begin{tabular}{|c|c|c|c|c|c|}
\hline FB & $9,81 \quad \mathrm{bA}$ & $10,66 \mathrm{aA}$ & $11,38 \mathrm{aA}$ & 7,26 & $\mathrm{aB}$ \\
\hline F2 & $12,65 \mathrm{aA}$ & $6,88 \mathrm{bB}$ & $9,94 \mathrm{aA}$ & 7,54 & $\mathrm{aB}$ \\
\hline $\mathrm{C}$ & $5,19 \mathrm{cA}$ & $4,13 \mathrm{cA}$ & $3,28 \mathrm{bA}$ & 2,61 & $\mathrm{bA}$ \\
\hline $\mathrm{R}$ & $1,42 \mathrm{dA}$ & $3,16 \mathrm{cA}$ & $2,10 \mathrm{bA}$ & 2,44 & $\mathrm{bA}$ \\
\hline \multirow[t]{3}{*}{ Média } & $7,27 \quad \mathrm{~A}$ & $6,21 \mathrm{~B}$ & 7,09 A & 4,77 & B \\
\hline & \multicolumn{5}{|c|}{ Açúcares solúveis, em mg de açúcares solúveis por g de peso fresco } \\
\hline & \multicolumn{5}{|c|}{$\mathrm{mg} \mathrm{g} \mathrm{pf}^{-1}$} \\
\hline FB & $7,42 \mathrm{aB}$ & $14,54 \mathrm{aA}$ & $7,16 \mathrm{aB}$ & 12,21 & $\mathrm{aA}$ \\
\hline F2 & $5,69 \mathrm{aB}$ & $8,12 \mathrm{bA}$ & 6,82 aA & 7,23 & $\mathrm{bA}$ \\
\hline $\mathrm{C}$ & 5,99 aA & $4,97 \mathrm{cA}$ & $3,43 \mathrm{bA}$ & 4,74 & $\mathrm{cA}$ \\
\hline $\mathrm{R}$ & $1,54 \mathrm{bB}$ & $3,27 \mathrm{cA}$ & $2,27 \mathrm{bA}$ & 2,61 & $\mathrm{dA}$ \\
\hline Média & $5,16 \quad \mathrm{~B}$ & $7,73 \mathrm{~A}$ & 5,16 B & 6,38 & A \\
\hline
\end{tabular}

Médias seguidas de mesma letra minúscula na coluna e mesma letra maiúscula na linha para cada dose de N, não diferem significativamente (Teste de Tukey, $\mathrm{p}<0,05$ ). Aos $133 \mathrm{DAG}$, as plantas estavam submetidas a $5 \mathrm{mg}$ de $\mathrm{N}_{-} \mathrm{NO}_{3}{ }^{-} \mathrm{L}^{-1}$, sendo submetidas no início do experimento a doses diferenciais de $\mathrm{N}\left(20\right.$ e $200 \mathrm{mg}$ de $\left.\mathrm{N}-\mathrm{NO}_{3}{ }^{-} \mathrm{L}^{-1}\right)$. DAG (dias após a germinação). 
Os teores de N-total na FB, F2 e C foram superiores na variedade Piauí quando comparada à variedade IAC-47 (Tabela 1). A FB e F2 proporcionaram os maiores teores de $\mathrm{N}^{-\mathrm{NH}_{4}}{ }^{+} \mathrm{em}$ ambas as variedades, quando cultivadas com $20 \mathrm{mg}$ de $\mathrm{N}-\mathrm{NO}_{3}{ }^{-} \mathrm{L}^{-1}$ no início do seu ciclo. Quando as plantas foram submetidas a $200 \mathrm{mg}$ de $\mathrm{N}-\mathrm{NO}_{3}{ }^{-} \mathrm{L}^{-1}$, o acúmulo de $\mathrm{N}_{-} \mathrm{NH}_{4}{ }^{+}$foi maior nas $\mathrm{FB}$ e F2. Em comparação com a variedade IAC-47, na variedade tradicional (Piauí) ocorreram maiores teores de N$\mathrm{NH}_{4}{ }^{+}$tanto na FB quanto na F2 (Tabela 1).

Os maiores teores de $\mathrm{N}^{-\mathrm{NO}_{3}}{ }^{-}$foram verificados nas $F B$ e F2, seguidos pelo $C$ e $R$, que não diferiram entre si, para ambas as variedades. No entanto, a variedade tradicional acumulou maiores teores de $\mathrm{N}$ $\mathrm{NO}_{3}{ }^{-}$em todas as partes analisadas da planta, em ambas as doses de $\mathrm{N}-\mathrm{NO}_{3}{ }^{-}$(Tabela 1 ).

$\mathrm{O}$ maior acúmulo de $\mathrm{N}-\mathrm{NO}_{3}{ }^{-}$nessa cultivar já havia sido demonstrado em outros estudos (Rodrigues et al., 2004; Souza e Fernandes, 2006), demonstrando seu potencial no acúmulo e uso eficiente de $\mathrm{N}$.

A FB e F2 parecem funcionar como órgãos de reserva de $\mathrm{N}$ para as plantas. No geral, quando as duas cultivares são comparadas, a tradicional (Piauí) acumula na FB e F2 maiores teores de N-total, $\mathrm{N}_{-} \mathrm{NH}_{4}{ }^{+}$ e $\mathrm{N}^{-\mathrm{NO}_{3}}{ }^{-}$(Tabela 1), portanto, com maior reserva de $\mathrm{N}$ quando comparada à variedade melhorada (IAC47). Esse comportamento também se reflete em maior massa fresca de colmo e raízes da variedade Piauí em relação à variedade IAC-47 (Tabela 1).

Os maiores teores de $\mathrm{N}$ constatados na FB e F2 da variedade Piauí sugerem maior potencial de translocação do $\mathrm{N}$ armazenado em seus tecidos, pois mesmo no fim do ciclo da cultura (133 DAG), nesta variedade ainda havia quantidade considerável de $\mathrm{N}$ nas folhas que suprem a panícula durante o enchimento de grãos (FB e F2). Este nitrogênio poderia ainda ser translocado, como apresentado por CRAWFORD e GLASS (1998). Segundo estes autores, o $\mathrm{NO}_{3}{ }^{-}$ absorvido em excesso pela planta pode ser estocado no vacúolo, servindo como fonte de $\mathrm{N}$ mineral quando o fornecimento pelo solo torna-se limitante.

Os dados apresentados neste experimento estão também de acordo com os resultados observados por Hirel et al. (2001), em que o aumento na produtividade de genótipos de milho foi devido a sua habilidade em acumular $\mathrm{NO}_{3}{ }^{-}$em suas folhas durante o crescimento vegetativo e sua eficiente remobilização durante o enchimento dos grãos.

Os maiores teores de $\mathrm{N}$-amino livre foram observados nas FB e F2 de ambas as cultivares independentemente da dose de $\mathrm{N}-\mathrm{NO}_{3}{ }^{-}$utilizada no cultivo (Tabela 1). Elevados teores de $\mathrm{N}$-amino livre podem ter contribuído para o acúmulo de $\mathrm{NO}_{3}{ }^{-}$nos tecidos, uma vez que estudos têm demonstrado que o $\mathrm{NO}_{3}{ }^{-}$e os produtos da sua redução influenciam sua aquisição e redução (SCHEIBLE et al. 1997). Em curto prazo, o conteúdo de aminoácidos aumenta quando $\mathrm{NO}_{3}{ }^{-}$e $\mathrm{NH}_{4}{ }^{+}$são fornecidos a folhas excisadas (FoYER et al., 1994)

O aumento nos teores de $\mathrm{NO}_{3}{ }^{-}$nos tecidos está relacionado também aos maiores teores de $\mathrm{N}$-amino livre, como demonstrado por Souza et al. (1999), em que a aplicação de doses crescentes de $\mathrm{N}$ na forma de URAN (fertilizante líquido contendo uréia, amônio e nitrato) levou a um aumento no teor de $\mathrm{N}$-amino livre e diminuição nos níveis de açúcares solúveis quando da aplicação da maior dose de $\mathrm{N}(60+60 \mathrm{~kg}$ Nha $\left.^{-1}\right)$.

Resultados similares foram constatados no presente estudo, em que para ambas as doses de $\mathrm{N}$ $\mathrm{NO}_{3}{ }^{-}$, na variedade tradicional Piauí, houve menores teores de açúcares solúveis, principalmente nas FB e $\mathrm{F} 2$, quando submetidas anteriormente à menor dose

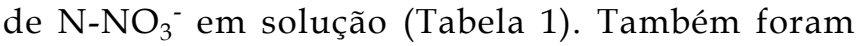
constatados maiores teores de $\mathrm{N}$-amino livre nas raízes de uma variedade tradicional de arroz (Lageado) quando submetida à maior dose de $\mathrm{N}^{-\mathrm{NO}_{3}}{ }^{-}$ (SANTOS et al., 2003).

Neste estudo, os dados indicam que ocorreu maior redução do $\mathrm{NO}_{3}{ }^{-}$nas raízes onde a atividade da NR foi alta para ambas as variedades, tanto quando estiveram submetidas a 20 quanto a $200 \mathrm{mg}$ de $\mathrm{N}-\mathrm{NO}_{3}{ }^{-} \mathrm{L}^{-1}$ de $\mathrm{N}$ (Figura 1 ).

Não houve diferença significativa na atividade da GS nas partes da planta da variedade Piauí quando submetida ao menor tratamento $(20 \mathrm{mg}$ de $\mathrm{N}$ $\left.\mathrm{NO}_{3}{ }^{-} \mathrm{L}^{-1}\right)$, enquanto para a maior dose $(200 \mathrm{mg}$ de $\mathrm{N}-\mathrm{NO}_{3}{ }^{-} \mathrm{L}^{-1}$ ), a atividade da GS foi superior na FB. Na cultivar IAC-47 ocorreu maior atividade da GS na FB em ambas as doses de $\mathrm{N}^{-\mathrm{NO}_{3}}{ }^{-}$(Figura 2). Quando a atividade média da GS é comparada entre as duas cultivares, pode ser observado que na 'IAC-47' a atividade da GS foi superior em ambos os tratamentos (Figura 3).

Há evidências revelando que para os cereais, a isoforma GS1 é a enzima-chave na mobilização do $\mathrm{N}$ das folhas senescentes (ANDrews et al., 2004). Esse fato poderia explicar a maior atividade da GS na cultivar melhorada, que estaria em processo de senescência mais acentuado que na cultivar tradicional Piauí, por não ter armazenado $\mathrm{N}$ nas fases anteriores do seu ciclo. 

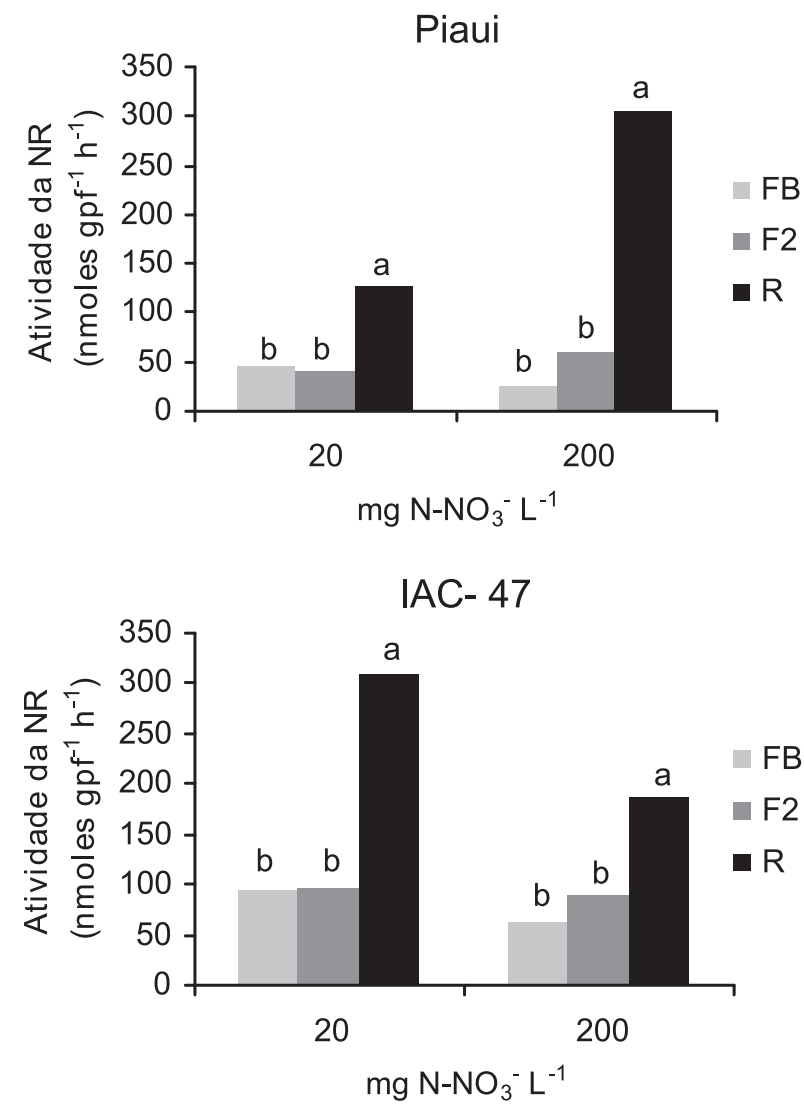

Figura 1. Atividade da nitrato redutase (NR) no fim do ciclo da cultura (133 DAG) na folha bandeira (FB), folha 2 (F2) e raízes (R) de duas cultivares de arroz submetidas a duas doses de $\mathrm{N}-\mathrm{NO}_{3}^{-}, 20$ e $200\left(\mathrm{mg}\right.$ de $\left.\mathrm{N}-\mathrm{NO}_{3}^{-} \mathrm{L}^{-1}\right)$. Letras minúsculas iguais em cada dose de $\mathrm{N}$ não diferem significativamente (Teste de Tukey, $p<0,05$ ).

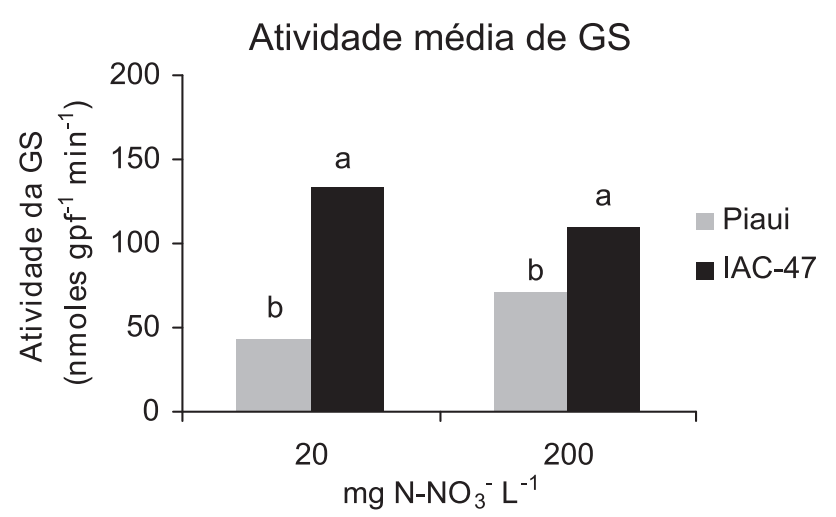

Figura 3. Atividade média da glutamina sintetase (GS) no fim do ciclo da cultura (133 DAG), em duas cultivares de arroz submetidas a duas doses de $\mathrm{N}-\mathrm{NO}_{3}{ }^{-}$ , 20 e 200 (mg de $\left.\mathrm{N}^{-\mathrm{NO}_{3}}{ }^{-} \mathrm{L}^{-1}\right)$. Letras minúsculas iguais em cada dose de $\mathrm{N}$ não diferem significativamente (Teste de Tukey, $\mathrm{p}<0,05$ ).
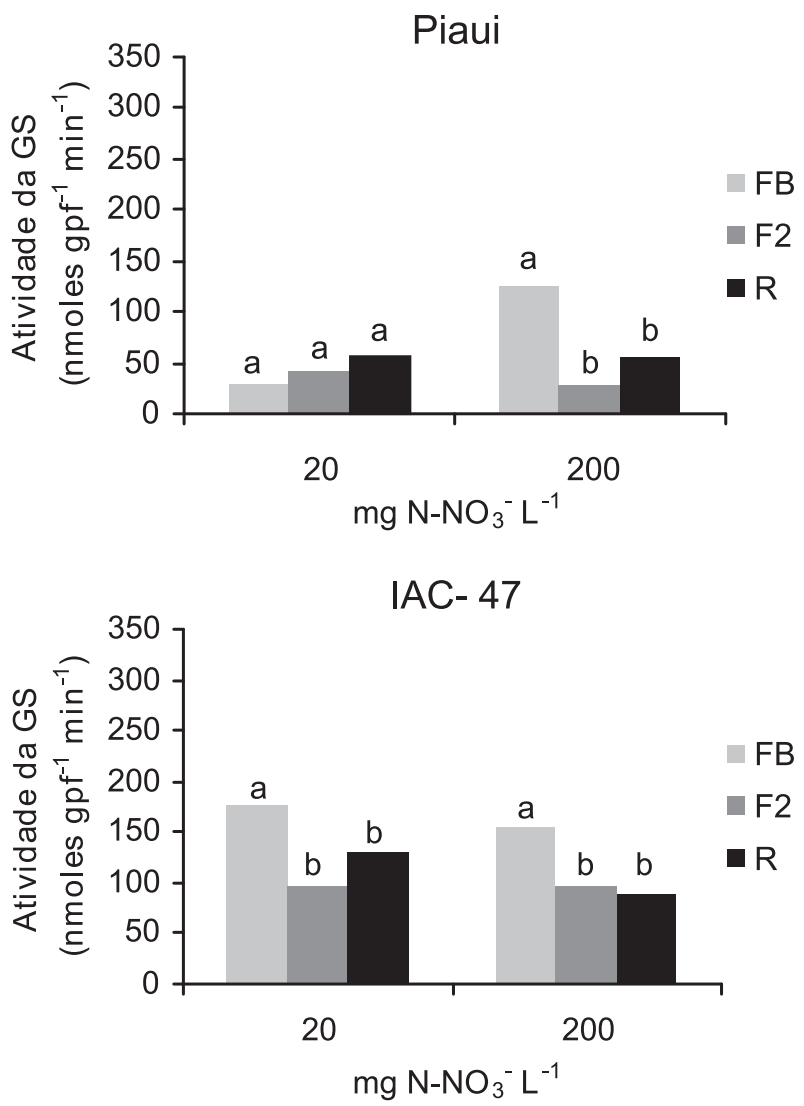

Figura 2. Atividade da glutamina sintetase (GS) no fim do ciclo da cultura (133 DAG) na folha bandeira (FB), folha 2 (F2) e raízes (R) de duas cultivares de arroz submetidas a duas doses de $\mathrm{N}-\mathrm{NO}_{3}{ }^{-}, 20$ e 200 (mg de $\mathrm{N}-\mathrm{NO}_{3}{ }^{-} \mathrm{L}^{-}$). Letras minúsculas iguais em cada dose de $\mathrm{N}$ não diferem significativamente (Teste de Tukey, $\mathrm{p}<0,05$ ).

\section{CONCLUSÕES}

1. Pelos resultados observam nas variedades estudadas comportamento diferenciado em relação ao acúmulo e à translocação de $\mathrm{N}$, quando submetidas ao fluxo sazonal de nitrato.

2. A cultivar tradicional Piauí parece acumular $\mathrm{NO}_{3}{ }^{-}$nas fases iniciais do desenvolvimento, o que pode permitir sua posterior translocação.

3. A folha bandeira e folha 2 parecem atuar como local preferencial de acúmulo de $\mathrm{N}$, sendo este acúmulo mais intenso na variedade Piauí.

\section{AGRADECIMENTOS}

Os autores agradecem ao CNPq, à CAPES e à FAPERJ pelas bolsas e pelo apoio financeiro. 


\section{REFERÊNCIAS}

ANDREWS, M.; LEA, P.J.; RAVEN, J.A.; LINDSEY, K. Can genetic manipulation of plant nitrogen assimilation enzymes result in increased crop yield and greater N-use efficiency? An assessment. Annals of Applied Biology, Wellesbourne, v.141, n.1, p.25-40, 2004.

CATALDO, D.; HARRON, M.; SCHARADER, L. E.; YOUNGS, V. L. Rapid colorimetric determination of nitrate in plant tissue by nitration of salicylic acid. Communication in Soil Science and Plant Analysis, New York, US, v.6, p.853-855, 1975.

CRAWFORD, N. M. and GLASS, A. D. M. Molecular and physiological aspects of nitrate uptake in plants. Trends in Plant Science, London, v.3, n.10, p.389-395, 1998.

FAO. Food Balances Sheets for 1995. Disponível em: http:// a p p s.f a o.o r g / 1 i m $500 / \mathrm{n} \mathrm{p} \mathrm{h} \mathrm{-}$ wrap.pl?FoodBalanceSheet\&Domain=FoodBalanceSheet. 1998.

FARNDEN, K. J. S.; ROBERTSON, J. G. Methods for studying enzyme envolved in metabolism related to nitrogen. In: BERGSEN, F.J. (Ed.). Methods for Evaluating Biological Nitrogen Fixation. Chilchester: John Wiley \& Sons, 1980. p.279-286.

FELKER, P. Microdetermination of nitrogen in seed protein extracts. Analytical Chemistry, Washington, v.49,1980, 1977.

FERNANDES, M. S. N-carriers, light and temperature influences on uptake and assimilation of nitrogen by rice. Turrialba, San Jose, v.34, p.9-18, 1984.

FERREIRA, D.F. Análises estatísticas por meio do Sisvar para Windows versão 4.0. In.: REUNIÃO ANUAL DA REGIÃO BRASILEIRA DA SOCIEDADE INTERNACIONAL DE BIOMETRIA, 45., 2000, São Carlos. Anais... São Carlos: UFSCar, 2000. p. 255-258.

FOYER, C.H.; NOCTOR, G.; LELANDOUS, M.; LESCURE, J.C.; VALADEIR, M.H.; BOUTIN, J.P.; HORTON, P. Short-term effects of nitrate, nitrite and ammonium assimilation on photosynthesis, carbon partitioning and protein phosphorylation in maize. Planta, Berlin, v.192, p.211-220, 1994.

GREENLAND, D.J. Nitrate fluctuations in tropical soils. Journal Agricultural Science, Tokyo, v.50, p.82-91, 1958.

HIREL, B.; BERTIN, P.; QUILLERÉ, I.; BOURDONCLE, W.; ATTAGNANT, C.; DELLAY, C.; GOUY, A.; CADIOU, S.; RETAILLIAU, C.; FALQUE, M. \& GALLAIS, A. Towards a Better Understanding of the Genetic and Physiological Basis for Nitrogen Use Efficiency in Maize. Plant Physiology, Sofia, v.125, p.1258-1270, 2001.

HOAGLAND, D. R. and ARNON, D. I. The water-culture method for growing plants without soil. Berkeley, US.: California Agricultural Experiment Station, 1950. 347p.

JAWORSKI, E. G. Nitrate Reductase Assay in intact Plant Tissues. Biochemical and Byophysical Research Communications, Duluth, v.43, n.6, p.1274-1279, 1971.
KHUSH, G.S. What it will take to Feed 5.0 Billion Rice consumers in 2030. Plant Molecular Biology, Dordrecht, v.59, p.1-6, 2005.

NARDOTO, G.B. and BUSTAMANTE, M.C. Effects of fire on soil nitrogen dynamics and microbial biomass in savannas of Central Brazil. Pesquisa Agropecuária Brasileira, Brasília, v.38, n.8, p.955-962, 2003.

RODRIGUES, F.S.; SOUZA, R.S.; RODRIGUES, F.S. and FERNANDES, M.S. Nitrogen metabolism in rice cultivated under seasonal flush of nitrate. Journal of Plant Nutrition, New York, v.27, p.395-409, 2004.

SANTOS, A.M.; STARK, E.M.L.M.; FERNANDES, M.S.; SOUZA, S.R. Teores de nitrogênio, fósforo e frações solúveis em duas variedades de arroz cultivadas em solução nutritiva sob dois níveis de nitrato. Agronomia, Rio de Janeiro, v.37, n.1. p.76-81, 2003.

SCHEIBLE, W.R.; LAURER, M.; SCHULZE, E.D.; CABOCHE, M.; STITT, M. Accumulation of nitrate in the shoots acts as a signal to regulate shoot-root allocation in tobacco. The Plant Journal, v.11, p.671-691, 1997.

SOUZA, S.R.; STARK, E.M.L.M.; FERNANDES, M.S. AND MAGALHÃES, J.R. Effects of Supplemental Nitrogen on Nitrogen-Assimilation Enzymes, Free Amino Nitrogen, Soluble Sugars, and Crude Protein of Rice. Communication in Soil Science and Plant Analysis, New York, v.30, n.5\&6, p.711-724, 1999.

SOUZA, S. R.; STARK, E. M. L. M. and FERNANDES, M. S. Nitrogen Remobilization During the Reproductive Period in Two Brazilian Rice Varieties. Journal of Plant Nutrition, New York, v.21, n.10, p.2049-2063, 1998.

SOUZA, S.R.; FERNANDES, M.S. Nitrogen-acquisition by plants in a sustainable environment. In: SINGH, R.P.;JAIWAL, P.K. (Ed.). Biotechnological Approaches to Improve Nitrogen Use Efficiency in Plants. Houston, Texas: Studium Press, 2006. p.41-62,

TEDESCO, M. J. Extração Simultânea de N, P, K, Ca e Mg em tecidos de plantas por digestão com $\mathrm{H}_{2} \mathrm{O}_{2} \mathrm{H}_{2} \mathrm{SO}_{4}$. 1983. n.p. (Apostila 23)

TILMAN, D. G. et al. Forecasting agriculturally driven global environmental change. Science, Washington, v.292, p.282-284, 2001.

WETSELAAR, R. Nitrate distribution in tropical soils. I. Possible cause of nitrate accumulation near the surface after a long dry period. Plant and Soil, Dordrecht, v.15, p.110-120, 1961a.

WETSELAAR, R. Nitrate distribution in tropical soils. II. Extent of capillary accumulation of nitrate during a long dry period. Plant and Soil, Dordrecht, v.15, p.121-133, 1961 b.

YEMM, E. W. and COCKING, E. C. The determination of animoacid with ninhydrin. Analytical Biochemistry, San Diego, v.80, p.209-213, 1955.

YEMM, E. W. and WILLIS, A. I. The estimation of carbohydrates in plant extracts by anthrone. Biochemical Journal, London, UK, v.57, p.508-514, 1957. 